Proceedings

\title{
Spray-Air Contact in Tall and Short-Type Spray Dryers Affects Important Physicochemical Properties of Microencapsulated Chia Seed Oil +
}

\author{
María Gabriela Bordón 1,2, Noelia P. X. Alasino 3, Maria Victoria Defaín Tesoriero ${ }^{4}$, \\ Nahuel Camacho 5, Maria C. Penci 1,2,3 and Marcela L. Martínez 1,3,6 and Pablo D. Ribotta 1,2,3,* \\ 1 Instituto de Ciencia y Tecnología de los Alimentos, Facultad de Ciencias Exactas, \\ Físicas y Naturales (ICTA-FCEFyN)-Universidad Nacional de Córdoba (UNC), 5000 Córdoba, Argentina; \\ gabrielabordon90@gmail.com (M.G.B.); cpenci@gmail.com (M.C.P.); \\ marcelamartinez78@hotmail.com (M.L.M.) \\ 2 Instituto de Ciencia y Tecnología de Alimentos Córdoba (ICYTAC, CONICET-UNC), 5000 Córdoba, \\ Argentina \\ 3 Departamento de Química Industrial y Aplicada (FCEFyN-UNC), 5000 Córdoba, Argentina; \\ nalasino@gmail.com \\ 4 Grupo de Sistemas de Liberación Controlada, Centro de Química, Instituto Nacional de Tecnología \\ Industrial (INTI), B6000XAL Buenos Aires, Argentina; mdefain@inti.gob.ar \\ 5 Unidad de Investigación y Desarrollo en Tecnología Farmacéutica (UNITEFA, CONICET-UNC), \\ 5000 Córdoba, Argentina; nahuelc03@gmail.com \\ 6 Instituto Multidisciplinario de Biología Vegetal (IMBIV, CONICET-UNC), 5000 Córdoba, Argentina \\ * Correspondence: pribotta@agro.unc.edu.ar \\ † Presented at the 2nd International Conference of Ia ValSe-Food Network, Lisbon, Portugal, \\ 21-22 October 2019.
}

Published: 27 August 2020

\begin{abstract}
The aim of this work was to determine the influence of the spray dryer's aspect ratio (height/diameter) on the physico-chemical properties of microencapsulated chia oil (CSO). Two different dryers were analyzed: a tall-type dryer $[H / D=5 / 1]$, and a short-type dryer $[H / D=1.65 / 1]$. The former corresponded to a co-current flow, while the latter had a central air disperser in the chamber, and a rotary air flow. Emulsions were prepared by homogenization of CSO, and a mixture of soy protein isolate (SPI) and gum arabic (GA). The co-current contact in the tall-type dryer yielded greater oxidative stability indexes (OSI) (three times higher than CSO), which was possibly associated the reduced thermal degradation. It can be concluded that a co-current contact constitutes a better alternative for the protection of CSO.
\end{abstract}

Keywords: chia seed oil; dryer aspect ratio; microencapsulation; oxidative stability; physical properties; spray-air contact

\section{Introduction}

Chia seed (Salvia hispanica L.) oil (CSO) is the major vegetable source of alpha-linolenic acid (ALA, C18:3); thus, the development of food fortified with chia has been extensively encouraged [1] However, CSO is highly susceptible to oxidation due to the unsaturated structure of its fatty acids [2], which ultimately decreases the nutritional value of the foods and negatively impacts their sensory properties [1]. Hence, the need for the protection of Omega-3-rich oils, through microencapsulation technologies is justified [1]. 
Spray drying is the most widespread technology in the microencapsulation field due to its low cost, flexibility and scalability [2]. Rapid water removal results in increased product shelf-life, and reduced shipping and storage costs $[3,4]$. The manner in which the sprayed feed contacts the drying air has a great bearing on the dried product's properties, due to its influence on the droplet behavior during drying. This contact is dictated by the position of the atomizer in relation to the air disperser [4]. Therefore, the spray can be directed into hot air with a co-current, counter-current or mixed flow [3]. Co-current configurations are preferred if heat-sensitive products (like CSO) are involved, given that the spray evaporation is rapid, the drying air cools accordingly, and the evaporation times are short. Nonetheless, any areas of back mixing in the drying chamber (local counter-current flow) may create an overly hot environment for heat-sensitive ingredients [4]. This important issue, although very clear, is rarely addressed in the scientific literature, with only theoretical studies [4].

Based on the above considerations, the present work aimed to analyze the influence of two different spray dryers' aspect ratios (height/diameter), and the spray-air contact therein, on the physico-chemical properties of microencapsulated CSO.

\section{Materials and Methods}

\subsection{Materials}

Chia seed oil (CSO) was extracted from seeds coming from Salta province (Nutracéutica Sturla SRL, Argentina), according to Martínez et al. [5], in a pilot plant screw press (Komet Model CA 59 G, IBG Monforts, Mönchengladbach, Germany). Soy protein isolate (SPI) SUPRO E with $90 \%$ protein on fat-free basis was purchased from The Solae Company (San Isidro, Argentina); gum arabic (GA) (Alland \& Robert, Paris and Normandy, France) and maltodextrin (MD) DE 5 (Lorelite 5, Companhia Lorenz, Indaial, Brazil) were purchased from a local distributor (Distribuidora NICCO, Córdoba, Argentina).

\subsection{Emulsion Preparation and Characterization}

Coarse emulsions were prepared by high-speed homogenization of CSO, and a mixture of SPI and GA (15,000 rpm, 2 min, Ultraturrax homogenizer IKA T18, Janke \& Kunkel GmbH, Staufen, Germany); 1/1 SPI/GA and 2/1 ((SPI+GA)/CSO) ratios (w/w) were used. The coarse emulsions were further homogenized in a high-pressure valve homogenizer at 700 bar $(1$ cycle, EmulsiFlex C5, Avestin, Ottawa, ON, Canada). The $\mathrm{pH}$ of fine emulsions was adjusted to 3.0 to induce coacervation between SPI and GA, and the reaction was completed with stirring at room temperature. Finally, MD DE 5 as filler was incorporated before drying to achieve a $22 \% \mathrm{w} / \mathrm{v}$ final total solid content.

Particle size distribution of final emulsions was determined according to Us-Medina et al. (2018), and with a LA 950V2 Horiba (Kyoto, Japan) analyzer.

Time-dependent steady shear properties of emulsions were evaluated using a controlled-stress rheometer MCR 301 Anton Paar, equipped with a plate-cone geometry (50 mm diameter) and working with a $0.05-\mathrm{mm}$ gap [6].

The morphology of oil droplets was assessed with a confocal scanning laser microscope (Olympus FV1000, Tokyo, Japan) according to González et al. [1], with brief modifications. The continuous phase was labeled with a fluorescent marker, Rhodamine B (Sigma-Aldrich, Darmstadt, Germany) (0.08 $\mathrm{g} \mathrm{kg}^{-1}$ on a dry matter basis).

\subsection{Spray Drying Experimental Design}

Two replicated factorial designs were carried out in different spray dryers. The factors analyzed were inlet air temperature (3 levels) and feed flow rate (2 levels). The first design was performed in a tall-form spray dryer (TF-SD), Büchi B-290 (Büchi Labortechnik AG, Flawil, Switzerland), equipped with a two-fluid nozzle atomizer. The aspect ratio was $5 / 1$ (height/diameter $=0.55 \mathrm{~m} / 0.11 \mathrm{~m})$. The evaluated values of inlet air temperature and feed flow rate were 130,160 and $190^{\circ} \mathrm{C}$, and 2.6 and 5.8 $\mathrm{mL} / \mathrm{min}$, respectively. Finally, the second design was performed in a short-form spray dryer (SF-SD), Niro Mobile Minor (Søborg, Denmark), with a rotary atomizer. The aspect ratio was 1.65/1 
(height/diameter $=1.40 \mathrm{~m} / 0.85 \mathrm{~m}$ ). The evaluated inlet air temperatures were the same as the previous design, and the feed flow rates were 10 and $15 \mathrm{~mL} / \mathrm{min}$.

\subsection{Powder Characterization}

The powders obtained with both spray dryers were characterized in terms of moisture content $(\mathrm{MC})$, water activity $\left(\mathrm{a}_{\mathrm{w}}\right)$ and particle size distribution $\left(\mathrm{d}_{43}\right.$ and $\mathrm{d}_{32}$ mean diameters, and $\mathrm{d}_{50}$ refer to volume-based distribution) as described by Us-Medina et al. (2018). The aggregation index (AI) of microparticles after the drying of chia oil-in-water emulsions was calculated according to Ma et al. [7].

Color determinations were performed with a CM600d spectrophotometer (Konica-Minolta, Tokyo, Japan) according to González et al. [1]. Whiteness (WI) and yellowness (YI) index, as well as the color change $(\Delta \mathrm{E}$ index) between a blank and an oil-loaded microparticle, were estimated as described by Rodriguez et al. [8]. Surface fat (SF) and encapsulation efficiency (EE) were assessed according to González et al. [1]. The powder flowability was determined using the Carr's Index (CI) and the Hausner Ratio (HR), as described by Rodriguez et al. [8]. The oxidative stability index (OSI) was determined by the Rancimat test $\left(100{ }^{\circ} \mathrm{C}, 20 \mathrm{~L} / \mathrm{h}\right.$ air flow rate) according to González et al. [1]. The thermal behavior of powders was evaluated by thermogravimetric analysis (TGA), and was compared with a blank microparticle. Samples were heated from 25 to $350{ }^{\circ} \mathrm{C}$ with a linear rate of 10 ${ }^{\circ} \mathrm{C} / \mathrm{min}$. Glass transition temperatures were determined by differential scanning calorimetry (DSC, TA Instruments, New Castle, DE, USA) with a linear heating rate of $20{ }^{\circ} \mathrm{C} / \mathrm{min}$. Finally, the microstructure of powders was assessed by scanning electron microscopy (SEM, LSM5 Pascal; Zeiss, Oberkochen, Germany) according to González et al. [1].

\section{Results and Discussion}

Many authors have highlighted the influence of parent emulsion characteristics on the final properties of powders, especially particle size distribution [9], which is useful for assessing the homogeneity of the system and tracking changes caused by processing transformations. Tiny and agglomerated oil droplets could be identified in emulsions (Figure 1) after complex coacervation of SPI and GA, which enhances the microparticles' mechanical strength [10]. As regards the rheological behavior of parent emulsions, the data were fit to the power law $\left(R^{2}>0.96\right)$. Flow index $(n)$ values in the range of $0.32-0.40$ were found, indicating a shear-thinning behavior. The consistency index $(k)$ was in the range of $2.40-3.00 \mathrm{~Pa} \mathrm{~s}^{\mathrm{n}}\left(0.1-300 \mathrm{~s}^{-1}\right.$ shear rate range). Finally, the viscosity value at $100 \mathrm{~s}^{-1}$ $\left(\eta_{100}\right)$, typical of many food processes, fell in the range of $0.111-0.155$ Pa s.

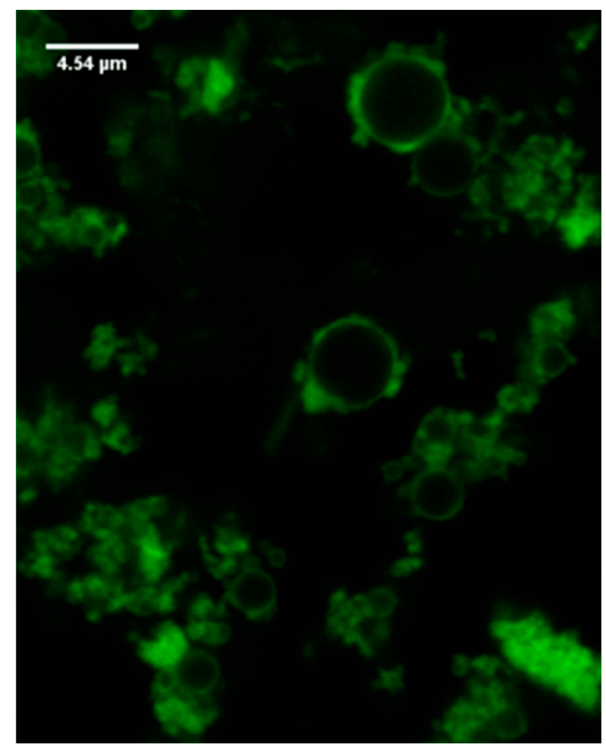

Figure 1. Confocal laser scanning microscopy (CLSM) images of parent chia seed-oil-in-water emulsions. 
Ranges for the particle size distribution of parent and reconstituted emulsions, as well as for the corresponding AI of powders, are shown in Table 1. In addition, the corresponding ranges for other physical properties can be found in Table 2 (MC, aw, SF, EE, CI and HR) and Table 3 (color parameters). The AI values for SF-SD microparticles were significantly higher $(p<0.05)$ than for TFSD microparticles, which may be explained by the particle agglomeration facilitated by rotary atomizers [4]. In addition, a strong positive correlation $(p<0.05)$ was found between AI and $\mathrm{d}_{43}(\mathrm{r}=$ 0.9916).

Table 1. Particle size parameters of parent and reconstituted emulsions.

\begin{tabular}{ccccc}
\hline & $\mathbf{d}_{43}$ & $\mathbf{d}_{32}$ & $\mathbf{d}_{50}$ & AI \\
\hline Parent emulsion & $21.10-21.20$ & $12.80-12.90$ & $12.21-12.30$ & -- \\
T-F SD ${ }^{\text {A }}$ & $8.70-16.80$ & $8.40-11.25$ & $8.50-11.46$ & $0.06-0.31$ \\
S-F SD в & $45.30-60.00$ & $9.50-13.20$ & $48.50-51.70$ & $3.00-4.30$ \\
\hline
\end{tabular}

A TF-SD (Tall-form spray dryer); ${ }^{\text {B } S F-S D ~(S h o r t-f o r m ~ s p r a y ~ d r y e r) . ~ T h e s e ~ a b b r e v i a t i o n s ~ h o l d ~ f o r ~ t h e ~}$ rest of the Tables. $\mathrm{d}_{43}$ (de Brouckere mean diameter, $\mu \mathrm{m}$ ); $\mathrm{d}_{32}$ (Sauter mean diameter, $\mu \mathrm{m}$ ); $\mathrm{d}_{50}$ (median diameter, volume distribution, $\mu \mathrm{m}$ ); AI (aggregation index). The lowest and the highest values in each range correspond to the maximum air inlet temperature and the minimum feed flow rate, and to the minimum air inlet temperature and the maximum feed flow rate, respectively.

Table 2. Moisture content, water activity, surface fat, encapsulation efficiency and flowing properties of powders.

\begin{tabular}{ccccccc}
\hline & MC & aw & SF & EE & CI & HR \\
\hline T-F SD & $3.10-4.50$ & $0.270-0.335$ & $7.00-10.50$ & $61.50-75.00$ & $40.20-46.30$ & $1.45-2.00$ \\
S-F SD & $5.08-6.55$ & $0.320-0.385$ & $0.25-2.10$ & $92.40-99.00$ & $31.50-49.60$ & $1.65-1.81$ \\
\hline
\end{tabular}

MC (moisture content, \% wet basis); aw (water activity); SF (surface fat, \% dry basis); EE (encapsulation efficiency, \% dry basis); CI (Carr's Index, \%); HR (Hausner ratio).

Table 3. Color parameters of powders.

\begin{tabular}{ccccccc}
\hline & $\mathbf{L}^{*}$ & $\mathbf{a}^{*}$ & $\mathbf{b}^{*}$ & $\Delta \mathbf{E}$ & $\mathbf{W I}$ & YI \\
\hline T-F SD & $91.10-94.05$ & $-0.19-0.10$ & $9.50-12.40$ & $2.30-3.65$ & $54.00-65.45$ & $16.80-19.50$ \\
S-F SD & $79.50-86.70$ & $-0.21-1.10$ & $14.20-18.05$ & $7.40-13.50$ & $32.40-44.05$ & $23.40-29.80$ \\
\hline
\end{tabular}

$\mathrm{L}^{*}$ (lightness); $\mathrm{a}^{*}$ (red-green component); $\mathrm{b}^{*}$ (yellow-blue component); $\Delta \mathrm{E}$ (color change index); $\mathrm{WI}$ (whiteness index); YI (yellowness index).

A significant reduction $(p<0.05)$ in OSI values was observed for SF-SD powders, compared with bulk CSO: $0.21-0.80 \mathrm{~h}$ and $3.00-3.33 \mathrm{~h}$, respectively. This may be related to eddies around the air disperser, which created local areas of counter-current flow between spray and air. On the other hand, the plug-flow air conditions in the chamber of a TF-SD are considerably different from the swirling air motion around the central disperser of the SF-SD, with less back mixing [4], thus preserving CSO from thermo-oxidative damage. For the TF-SD, the OSI values were in the range of $5.10-6.60 \mathrm{~h}$.

The lowest and the highest values in each range correspond to the maximum air inlet temperature and the minimum feed flow rate, and to the minimum air inlet temperature and the maximum feed flow rate, respectively.

Strong correlations $(p<0.05)$ were also found between OSI and WI $(r=0.9358), L^{*}(r=0.9079)$, YI $(r=-0.9029)$ and $\Delta E(r=-0.9410)$. Color changes are a sign of the oxidative deterioration of triacylglycerols and fatty acids, since this process can yield colored products [8]. In this regard, it is important to highlight that blank microparticles showed $\mathrm{L}^{*}, \mathrm{a}^{*}, \mathrm{~b}^{*}$, WI and YI values in the ranges of $90.80-92.00,-0.03-0.05,8.80-8.90,65.40-65.50$ and 13.70-13.80, respectively. Significant differences were observed $(p<0.05)$ between blank and SF-SD microparticles, as reflected by their higher values for $\triangle \mathrm{E}$ compared to TF-SD powders, which was in consonance with greater oxidative damage. 
The lowest and the highest values in each range correspond to the maximum air inlet temperature and the minimum feed flow rate, and to the minimum air inlet temperature and the maximum feed flow rate, respectively.

The particle size distributions and color parameters of the powders were also correlated $(p<$ $0.05)$, as expected: WI- $\mathrm{d}_{43}(\mathrm{r}=-0.9540)$ and WI-AI $(\mathrm{r}=-0.9627)$. Finally, a higher EE was associated with greater values of $\mathrm{d}_{43}(\mathrm{r}=0.9283)$ and $\mathrm{AI}(\mathrm{r}=0.9543)$.

As regards the flowing properties, $\mathrm{CI}>25 \%$ and $\mathrm{HR}>1.4$ were observed, evidencing a poor flowability and strong inter-particle forces [8].

SEM micrographs of powders (Figure 2) showed tiny agglomerates, especially for a TF-SD, which are typically produced by twin-fluid atomizers and aid in the redispersion process [4]. On the other hand, round-shaped particles of greater size and no evident agglomerates were observed for the SF-SD.

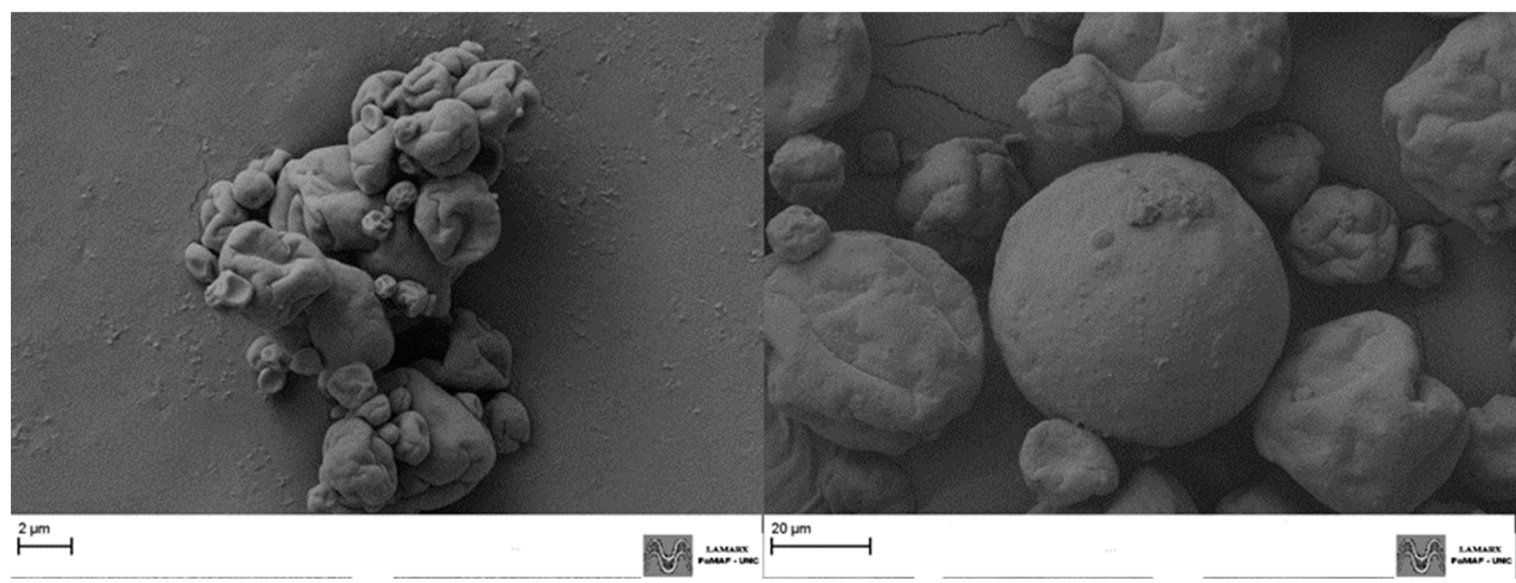

Figure 2. Scanning electron microscopy (SEM) images for microencapsulated chia seed oils. (First image) TF-SD. (Second image) SF-SD.

The thermal performance of the powders compared with a blank microparticle was assessed. It was found that all formulations showed two main stages of mass loss (curves not shown). The first stage, below $100{ }^{\circ} \mathrm{C}$, was related to the loss of adsorbed and bound water, and had a small weight loss for all microparticles. The onset temperatures for the second degradation stage were around 250$260{ }^{\circ} \mathrm{C}$ for all samples. These temperatures were in consonance with values reported for the wall materials of the present work, and corresponded to SPI pyrolysis $\left(\sim 270{ }^{\circ} \mathrm{C}\right.$, Song et al. [11]) and the thermal degradation profile of polysaccharides (Castro-Cabado et al. [12]). Finally, glass transition temperatures (Figure 3), as shown by the DSC curves, were around 172,169 and $186^{\circ} \mathrm{C}$ for blank, TFSD and SF-SD microparticles, respectively, in accordance with the reported values for MD DE 5 [3], GA (Barros Fernandes et al. [13]) and SPI (Tang et al. [14]). 


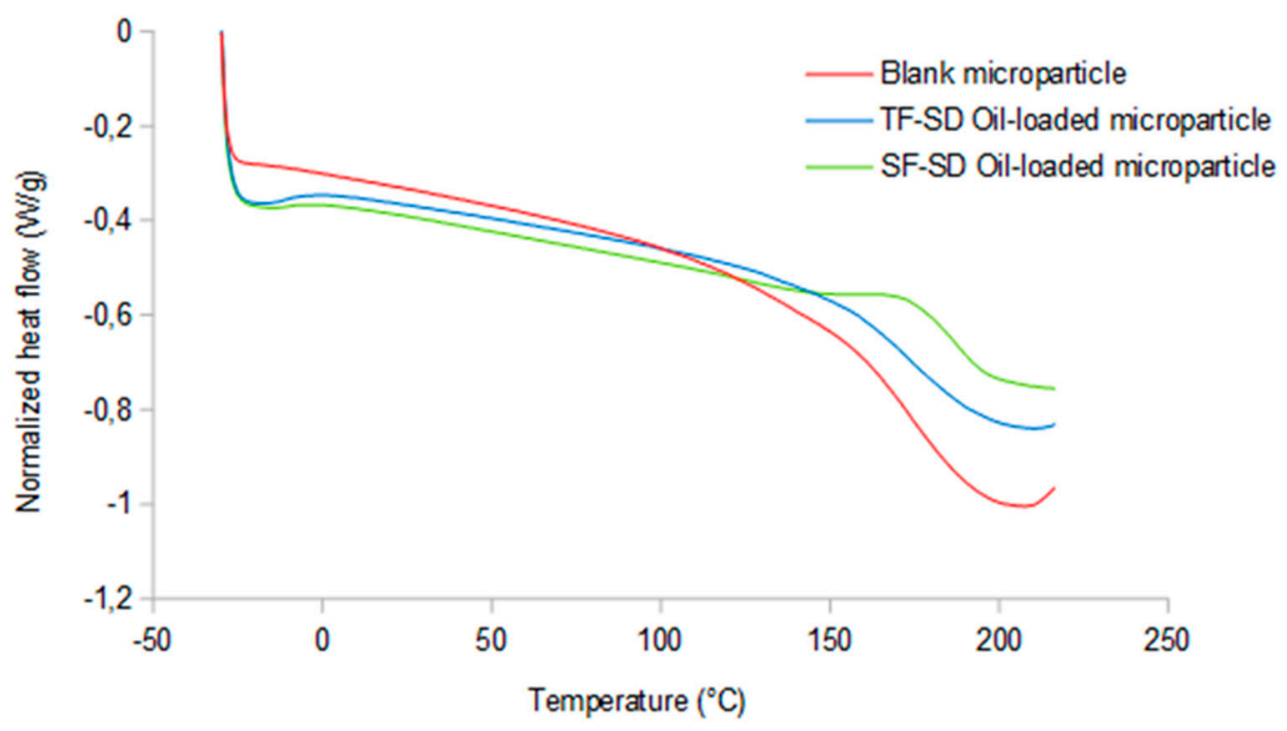

Figure 3. Differential scanning calorimetry (DSC) curves for blank and chia seed oil-loaded microparticles.

\section{Conclusions}

The physico-chemical properties of microencapsulated CSO proved to be greatly affected by the spray dryer's aspect ratio and by the spray-air contact. Turbulence around the air disperser in the SFSD created local areas of counter-current flow between spray and air, damaging the oil chemical quality. $\mathrm{L}^{*}, \mathrm{WI}, \mathrm{YI}$ and $\Delta \mathrm{E}$ values varied accordingly. However, a greater EE was achieved in the same SF-SD, which was associated with higher $\mathrm{d}_{43}$ and $\mathrm{AI}$ values. It can be concluded that a co-current spray-air contact constitutes a better alternative for the protection of a heat-sensitive ingredient like CSO.

Author Contributions: (M.G.B \& N.C.): methodology, investigation; (M.G.B, N.P.X.A, M.C.P., V.D.T., M.L.M. \& P.D.R.): methodology, conceptualization, formal analysis; (M.G.B \& M.L.M.): writing; (V.D.T., M.L.M. \& P.D.R.): supervision, project administration, funding acquisition.

Acknowledgments: The authors would like to acknowledge the Iberoamerican Project CYTED 119RT0567.

Funding: This work was supported by grant Ia ValSe-Food-CYTED (Ref. 119RT0567), Fondo para la Investigación Científica y Tecnológica (FONCyT, BID PICT 2014-2283, and PICT 2016-1150) and SeCyT-UNC.

Conflicts of Interest: The authors declare no conflict of interest.

\section{References}

1. González, A.; Martínez, M.; León, A.E.; Ribotta, P.D. Effects on bread and oil quality after functionalization with microencapsulated chia oil. J. Sci. Food Agric. 2018, 98, 4903-4910, doi:10.1002/jsfa.9022.

2. Timilsena, Y.P.; Adhikari, R.; Barrow, C.J.; Adhikari, B. Microencapsulation of chia seed oil using chia seed protein isolate chia seed gum complex coacervates. Int. J. Biol. Macromol. 2016, 91, 347-357, doi:10.1016/j.ijbiomac.2016.05.058.

3. Anandharanakrishnan, C.; Ishwarya, S. Spray Drying Techniques for Food Ingredient Encapsulation; John Wiley \& Sons, Ltd.: Chichester, UK, 2015; ISBN: 978-1-118-86419-7.

4. Masters, K. Spray Drying Handbook, 3rd ed.; Chapter 1; Halsted Press: New York, NY, USA; John Wiley \& Sons Inc.: Hoboken, NJ, USA, 1979. Available online: https://trove.nla.gov.au/work/6866065 (accessed on 20 May 2019).

5. Martínez, M.; Marin, M.; Salgado, C.; Revol, J.; Penci, M.; Ribotta, P. Chia (Salvia hispanica L.) oil extraction: Study of processing parameters. LWT-Food Sci. Technol. 2012, 47, 78-82, doi:10.1016/j.1wt.2011.12.032. 
6. González, A.; Gastelú; G; Barrera, G.N.; Álvarez Igarzabal, C.I. Preparation and characterization of soy protein films reinforced with celloluse nanofibers obtained from soybean by-products. Food Hydrocoll. 2019, 89, 758-764, doi:10.1016/j.foodhyd.2018.11.051.

7. Ma, T.; Zhao, H.; Wang, J.; Sun, B. Effect of processing condition on the morphology and oxidative stability of lipid microcapsules during complex coacervation. Food Hydrocoll. 2019, 87, 637-643, doi:10.1016/j.foodhyd.2018.08.053.

8. Rodríguez, E.S.; Julio, L.M.; Henning, C.; Diehl, B.W.K.; Tomás, M.C.; Ixtaina, V.Y. Effect of natural antioxidants on the physicochemical properties and stability of freeze-dried microencapsulated chia seed oil. J. Sci. Food Agric. 2018, doi:10.1002/jsfa.935.

9. Us-Medina, U.; Julio, L.M.; Segura-Campos, M.R.; Ixtaina, V.Y.; Tomás, M.C. Development and characterization of spray-dried chia oil microcapsules using by-products from chia as wall material. Powder Technol. 2018, 334, 1-8, doi:10.1016/j.powtec.2018.04.060.

10. Ach, D.; Briançon, S.; Broze, G.; Puel, F.; Rivoire, A.; Galvan, J.-M.; Chevalier, Y. Formation of microcapsules by complex coacervation. Can J Chem Eng. 2015, 93, 183-192, doi:10.1002/cjce.22086.

11. Song, X.; Zhou, C.; Fu, F.; Zhilin, C.; Qinling, W. Effect of high-pressure homogenization on particle size and film properties of soy protein isolate. Ind. Crops Prod. 2013, 43, 538-544, doi:10.1016/j.indcrop.2012.08.005.

12. Castro-Cabado, M.; Parra-Ruiz, F.J.; Casado, A.L.; San Román, J. Thermal crosslinking of maltodextrin and citric acid. Methodology to control the polycondensation reaction under processing conditions. Polym. Polym. Compos. 2016, 24, 643-653, doi:10.1177/096739111602400803.

13. de Barros Fernandes, R.V.; Borges, S.V.; Botrel, D.A. Gum arabic/starch/maltodextrin/inulin as wall materials on the microencapsulation of rosemary essential oil. Carbohydr. Polym. 2013, 101, 524-532, doi:10.1016/j.carbpol.2013.09.083.

14. Tang, C.-H.; Chen, Z.; Li, L.; Yang, X.-Q. Effects of transglutaminase treatment on the thermal properties of soy protein isolates. Food Res. Int. 2006, 39, 704-711, doi:10.1016/j.foodres.2006.01.012. 